\title{
2020, un año marcado por la pandemia de la enfermedad COVID-19
}

\author{
2020, a year marked by the COVID-19 pandemic
}

Este año 2020, ha estado marcado por la pandemia de la COVID-19, que afectó nuestro quehacer clínico y académico, modificando nuestras prácticas incluyendo el uso de medidas de protección en atención presencial de pacientes ambulatorios y hospitalizados así como la necesidad de implementar estrictos protocolos en las unidades de endoscopia, debido al mayor riesgo potencial de contagio por efecto aerosol. Debemos estar orgullosos del manejo realizado por los gastroenterólogos, miembros de la Sociedad Chilena de Gastroenterología, quienes sintieron un apoyo concreto de parte de nuestra Sociedad, así como de las Asociaciones y Filiales, que a través de cartas y recomendaciones publicadas en Gastroenterología Latinoamericana, pudieron implementar medidas de seguridad para sus pacientes y el personal de salud, que fueron basados en la mejor evidencia científica disponible, y que permitieron la atención de pacientes gastroenterológicos, con condiciones particulares como inmunosuprimidos o pacientes con daño hepático crónico que generaban incertidumbre en sus tratantes. También lamentamos el fallecimiento de pacientes y colegas, destacando la pérdida del Dr. René Sánchez. Por otra parte, tuvimos momentos de alegría como el reconocimiento de la trayectoria del Dr. Vicente Valdivieso, gastroenterólogo y miembro de nuestra Sociedad, quien recibió el Premio Nacional de Medicina 2020, que se suma a los Dres. Alejandro Goic (2006); Esteban Parrochia (2008) y Rodolfo Armas Merino (2010), marcando un liderazgo y gran influencia de nuestra especialidad en el panorama nacional, y en cierta medida, es un reconocimiento a los aportes sustanciales que nuestros miembros han realizado por décadas, en relación a avances científicos, políticas públicas, y formación de médicos-cirujanos, internistas y gastroenterólogos.

En la sección de artículos originales, los autores Romina Rey, Martín Elizondo, Sofía Rostán, Marcelo Valverde y Solange Gerona, nos presentan los resultados del análisis de una serie de casos con Síndrome de Budd-Chiari, incluyendo una interesante revisión del tema.

En la sección de artículos de revisión, destacamos el trabajo realizado por los Dres. Alejandro Villalón, Diego Reyes, Javier Ortiz, Vicente Gándara, Luis A. Díaz, Javier Chahuán, Margarita Pizarro y Arnoldo Riquelme, sobre el Tratamiento y manejo de la infección por Helicobacter pylori. Este artículo, es un complemento del artículo de diagnóstico y métodos de detección de esta infección tan prevalente en nuestro país, y que ha presentado cambios sustanciales en su manejo, debido a la incorporación de métodos no invasivos para su diagnóstico así como el uso de PCR y cultivos para detección de resistencia antibiótica, que han modificado el tratamiento estándar debido a la aparición de resistencia a claritromicina.

La sección de casos clínicos incluyen: Fístula portobiliar como complicación mayor de biopsia hepática transpercutánea bajo marcación ecográfica, que es presentado por Francisca Rivera y Diego San Martín. Otro caso destacado está relacionado con el uso de Necrosectomía endoscópica asistida por laparoscopia, como un enfoque terapéutico y que constituye una alternativa efectiva en el manejo de la necrosis pancreática infectada. Este caso clínico es presentado por Flávia Fernanda de França, Izabella Maria Lopes Titon, Jonas Takada, Nickson Santana Souto, Rafael Antunes Delfes, Fernanda Kreve y Francisco Schossler Loss.

En la sección de Medicina basada en la evidencia en Gastroenterología, contamos con el análisis crítico de 2 artículos de estudios aleatorizados prospectivos. El primer análisis trata sobre el uso de gastrectomía y quimioterapia en cáncer gástrico con factor único no curable. Es un estudio clínico controlado randomizado fase 3, analizado por Alexandra Elimelech, Natalia Molina, Francisca Aguilera, Luis Díaz, Arnoldo Riquelme y Gonzalo Pizarro.

El segundo artículo fue analizado por Rodrigo Arias, Vicente Gándara, María Francisca Seydewitz, Gonzalo Latorre, Margarita Pizarro y Arnoldo Riquelme, que describe sobre los efectos del tratamiento de Helicobacter pylori y de la suplementación con vitaminas y ajo en la incidencia y mortalidad de cáncer gástrico. 


\section{Editorial}

Finalmente, en la sección de "Gastroenterología y Algo más" el Dr. Juan Pablo Roblero nos trae un emotivo artículo en memoria del Dr. Héctor Orrego Matte.

Esperamos que este año, sea una instancia de aprendizaje para nuestros pacientes, familiares, equipos de salud y líderes en salud, para que podamos enfrentar de la mejor manera posible, los desafíos que se presenten en el futuro, ya que sin una vacuna efectiva, podemos volver a vivir un peak que desafíe la capacidad hospitalaria de nuestro país, y debemos estar preparados, para aprender de nuestros aciertos y desaciertos, resolviendo de manera cooperativa y con unidad, los problemas de salud vinculados a la pandemia, incluyendo el manejo agudo de las manifestaciones gastrointestinales, así como las secuelas que pudieran desarrollarlos pacientes.

Dr. Arnoldo Riquelme P.

Editor

Revista Gastroenterología Latinoamericana 